\title{
Efficacy and safety of cold snare resection in preventive screening colonoscopy
}

\section{(ㄷ)(1) $\odot$}

Authors

B. Schett ${ }^{1}$, J. Wallner ${ }^{1}$, V. Weingart ${ }^{1}$, A. Ayvaz ${ }^{1}$, U. Richter ${ }^{2}$, J. Stahl' ${ }^{2}$, H.-D. Allescher ${ }^{1}$

Institutions

1 Zentrum für Innere Medizin, Klinikum GarmischPartenkirchen, Auenstr. 6, 82467 Garmisch-

Partenkirchen, Germany

2 Institut für Pathologie, Klinikum GarmischPartenkirchen, Auenstr. 6, 82467 GarmischPartenkirchen, Germany

submitted 10.8.2016

accepted after revision 10.2.2017

\author{
Bibliography \\ DOI https://doi.org/10.1055/s-0043-105491 | \\ Endoscopy International Open 2017; 05: E580-E586 \\ (c) Georg Thieme Verlag KG Stuttgart · New York \\ ISSN 2364-3722
}

Corresponding author

Dr. B. Schett, Zentrum Innere Medizin, Klinikum GarmischPartenkirchen, Auenstraße 6, 82467 Garmisch-

Partenkirchen, Germany

Fax: +49-8821-771502

bernhard.schett@klinikum-gap.de

\section{ABSTRACT}

Background and aim Removal of polyps during colonoscopy effectively prevents the development of colorectal cancer. So far, snare resection with high frequency current with or without prior submucosal saline injection is the method of choice. The aim of this study was to evaluate the feasibility, safety, and outcome of cold snare resection during routine endoscopy.

Methods In this prospective study, 522 patients undergoing outpatient colonoscopy were included. Cold snare resection for diminutive $(<6 \mathrm{~mm})$, small $(6-9 \mathrm{~mm})$, and larger polyps $(>9-15 \mathrm{~mm}$ ) was performed using a dedicated cold snare device (Exacto ${ }^{\circledR}$ ) without prior submucosal injection. Outcome parameters included bleeding rate, perforation rate, procedure time, histologic evaluation of polyp margins, and success rates. The data were compared to a group of patients undergoing hot snare resection.

Results Overall, 1233 polyps were removed using cold snare resection with an overall success rate of $99.4 \%$. All failures of cold snare resection occurred in the cecum (8/ 82 , failure rate $9.8 \%$ ). In the remaining colon, the success rate was $100 \%$. Immediate post-polypectomy bleeding occurred in $0.49 \%$ of all patients and was most frequently seen in polyps larger than $9 \mathrm{~mm}$. The procedure time was significantly shorter using cold snare resection compared with hot snare resection $(27.6 \mathrm{~min}$ vs. $35.7 \mathrm{~min}, P<0.01)$. Conclusion Cold snare resection can be performed safely in outpatients for removal of small polyps in screening colonoscopy. It does not require prior saline injection and reduces procedure time without an increased risk of bleeding.

\section{Introduction}

Colonoscopy is the standard procedure for the detection of polyps, and colonoscopic polypectomy is most efficient in the prevention of colorectal carcinoma [1]. A range of endoscopic resection techniques is available for the removal of endoscopically detected polyps: cold biopsy forceps, hot biopsy forceps, cold snare excision, standard snare excision with electrocautery, piecemeal excision, and endoscopic submucosal dissection. The choice of resection technique depends on the polyp size, characteristics, and location. Polyps up to $5 \mathrm{~mm}$ in diameter are classed as diminutive while polyps in the range $6-9 \mathrm{~mm}$ are classified as small. In clinical practice, forceps techniques (cold and hot) are widely adopted for diminutive polyps whereas electrosurgical snare resection is preferred for small polyps $>5 \mathrm{~mm}$ in diameter [2].

Polypectomy is the most important tool in preventing colonic cancer; however, this technique is associated with risks such as perforation, bleeding, and post-polypectomy syndrome [3]. Resection can be tedious and time consuming, particularly in flat and multiple small polyps, as a result of prior saline injection or because multiple attempts may be required if a forceps is used. Different polypectomy techniques are used depending on the polyp size.

Diminutive $(1-5 \mathrm{~mm})$ and small $(6-9 \mathrm{~mm})$ polyps have the highest prevalence [4] but they also have the lowest risk of malignancy. Therefore, the risks associated with their removal should be as low as possible. 
Cold forceps removal has a low risk of perforation due to the absence of electrocautery (which results in tissue injury that can lead to perforation). However, forceps techniques are often ineffective with regard to complete resection, which is only achieved in $51-79 \%$ of cases using cold biopsy techniques. This might explain the relative high recurrence rate of up to 30 $\%$ after forceps removal [5-7].

Hot snare techniques have been shown to be more effective, as residual polyp tissue was left behind in $6.9 \%$ of small polyps [8]. Two other studies reported complete removal rates of $93-$ $96 \%[5,13]$. However, electrosurgical snares have a higher risk of perforation and delayed post-polypectomy bleeding $(0.26 \%$ perforations and $0.9 \%$ major hemorrhages) [9]. A comparative study showed that delayed post-polypectomy bleeding was more frequent in hot snare resection than in cold snare resection ( $14 \%$ vs. $0 \%$ in patients receiving anticoagulants) [10]. In addition, it can be assumed that the cautery reaction at the resection border cannot be evaluated by histological analysis due to thermal coagulation of tissue.

Earlier trials confirmed that cold snare excision is a safe and effective method for the removal of diminutive and small polyps [11-13]. Even with larger polyps (mean size $20 \mathrm{~mm}$ ), cold snare resection had a favorable safety profile [14].

Several studies have shown that cold snare resection has an equivalent histological eradication rate to hot snare resection $(93.2-96 \%)[6,10,13]$. Using a suction pseudopolyp technique, a complete histological excision rate of $98.6 \%$ can be achieved without adverse effects [15]. Cold snare polypectomy proved to be superior to cold forceps polypectomy in polyps $>4 \mathrm{~mm}$ with regard to complete resection [16]. Only in polyps up to $3 \mathrm{~mm}$ was the failure rate of tissue retrieval higher in cold snare resection compared with cold forceps resection [17]. Intraprocedural bleeding occurred in $1.8-5.7 \%$ of patients treated with anticoagulants $[4,13]$. No cases of delayed bleeding or perforation were observed.

A randomized pilot study compared the different removal methods (cold forceps, cold snare with injection, and hot snare with injection). No significant differences were observed, but this could be due to the small number of polyps removed. Overall, $9 \%$ incomplete removals were documented [18].

Taking into account the risks involved when using electrocautery including perforation and bleeding, and the lack of efficacy of cold forceps biopsy, the use of cold snare resection may be a reasonable choice for the resection of polyps.

Therefore, the aim of the present monocentric, prospective study was to analyze the feasibility, safety, and efficacy of cold snare resection using a cold snare device $\left(\right.$ Exacto ${ }^{\circledR}$ ). Feasibility was analyzed based on the location and size of the polyps removed. Safety was analyzed with respect to immediate postpolypectomy bleeding and perforation, whereas efficacy was evaluated based on the procedure time in patients with polyps $>6 \mathrm{~mm}$.

\section{Methods}

\section{Study design}

This single center, prospective study was conducted at the Center of Internal Medicine in the Hospital of Garmisch-Partenkirchen, Germany. The study was evaluated and approved by the institutional review board (IRB) and the local ethics committee. Informed consent was obtained from each patient 24 hours before the endoscopic procedure.

\section{Patients}

The study included patients undergoing colonoscopy for colorectal cancer screening or for symptoms in a 28-month period from January 2012 to April 2014. Eligible patients had at least one polyp with diameter in the range $4 \mathrm{~mm}$ to $\leq 15 \mathrm{~mm}$. The inclusion criteria for cold snare resection were only based on the size of the polyps. There was no exclusion based on the location or shape of the polyp. All polyps found during the endoscopic procedure were removed. If polyps larger than $15 \mathrm{~mm}$ were removed with hot snare in addition to a cold snare resection (mixed procedure), these patients were not included.

Polyps $<4 \mathrm{~mm}$ diameter were all removed with cold forceps. These patients were only evaluated if cold or hot snare resection was also performed. They were not evaluated for analysis of the withdrawal time.

Patients who received anticoagulants or adenosine diphosphate (ADP) receptor inhibitors were excluded. Antiplatelet therapy with acetylsalicylic acid was not an exclusion criterion.

All patients were informed about the resection methods and the possible associated adverse effects and written informed consent was obtained from each patient.

\section{Endoscopy procedure}

Colorectal endoscopic examination was performed using a high definition video endoscope (Olympus Videocolonoscope CF-HQ 180 or CF-HQ 190). For bowel preparation, at least $4 \mathrm{~L}$ of polyethylene glycol solution was used. For sedation, patients received propofol alone or propofol in combination with a small dose of midazolam $(2.5 \mathrm{mg})$; for withdrawal, $20 \mathrm{mg}$ of butylscopolamine was administered.

The polypectomy procedure was performed in a strictly standardized manner. All polyps smaller than $4 \mathrm{~mm}$ were removed by cold forceps biopsy. These polyps were not included in the study. All polyps between 4 and $15 \mathrm{~mm}$ diameter were removed either by cold snare resection without prior submucosal injection or by standard snare resection using an electrosurgical snare (Olympus SnareMaster, $15 \mathrm{~mm}, 0.47 \mathrm{~mm}$ wire, $230 \mathrm{~cm}$ length and an ERBE HF Generator) after submucosal injection of $1-5 \mathrm{~mL}$ saline. All patients with larger polyps (>15 mm) were excluded from the study and from the evaluation. Larger polyps requiring EMR or ESD were not included in the evaluation.

Polyp size, location, time to advance and withdraw the endoscope as well as immediate or late adverse effects were documented. All retrieved polyps underwent histological examination. Prophylactic clip application was left up to the 
endoscopist in higher risk patients, e.g. medication with acetylsalicylic acid (ASA) or large polyp size. Therapeutic clip application was performed when immediate bleeding occurred (Olympus Clip).

All procedures were performed by experienced endoscopists who had performed more than 10000 colonoscopies.

\section{Cold snare resection}

All cold snare resections were performed with the Exacto ${ }^{\circledR}$ cold snare device $(9 \mathrm{~mm}$ snare size, $230 \mathrm{~cm}$ length, $2.4 \mathrm{~mm}$ sheath diameter, braided snare wire; US Endoscopy, Ohio, United States). In eligible polyps, removal was carried out without prior submucosal injection of saline. After placement of the snare luminal, the wire loop was placed around the polyp. The polyps were resected by closing the snare; subsequently, they were suctioned through the endoscope work channel and collected separately.

\section{Outcome measurements}

The feasibility of cold snare resection was analyzed based on different colon locations as well as the size of resected polyps. Feasibility was defined as successful removal of a given polyp at a given colonic site.

Success was defined as macroscopic complete removal of a polyp with the intended method.

The safety of cold snare resection was analyzed based on immediate post-polypectomy bleeding and perforation. We did not use the term intraoperative or postoperative bleeding, but used the term immediate post-polypectomy bleeding. Immediate post-polypectomy bleeding was defined as bleeding which was not self-limiting within 2 minutes and required additional interventional hemostasis. Delayed bleeding was defined as a bleeding requiring medical treatment or emergency endoscopy (drop in hemoglobin) within 7 days after the procedure.

Efficacy was evaluated based on the procedure time in patients undergoing cold snare resection or hot snare resection of polyps $\geq 6 \mathrm{~mm}$. The time for advancing and withdrawing the colonoscope was recorded in all patients in a standardized manner.

Hot snare excision with electrocautery leads to coagulation artifacts at the margins, which might influence the histological evaluation of complete resection. Coagulation artifacts and complete resection in hot and cold snare resection were assessed by two independent pathologists (R.J., S.U.).

\section{Results}

A detailed analysis of the polyps removed by cold snare resection and their locations is given in > Table $\mathbf{1}$ and $>$ Table 2 .

Overall, 560 patients were recruited and included in the study. Cold snare resection was performed in 522 patients; snare resection using electrocautery was used in 38 patients. In the cold snare group, the overall number of polyps detected was 1233 . Most polyps were located in the left colon and predominantly in the sigmoid colon ( Table 1 ). With regard to polyp size, most polyps evaluated were small polyps with a diameter of $6-9 \mathrm{~mm}$ (58.2\%), followed by diminutive polyps
- Table 1 Characteristics of the location, size, and shape of the evaluated polyps removed by cold snare resection.

\begin{tabular}{|c|c|}
\hline Characteristic & n (\%) \\
\hline Number of polyps & 1233 \\
\hline \multicolumn{2}{|l|}{ Location } \\
\hline - Cecum & $82(6.7 \%)$ \\
\hline - Ascending colon & $226(18.3 \%)$ \\
\hline - Transverse colon & $240(19.5 \%)$ \\
\hline - Descending colon & $135(10.9 \%)$ \\
\hline - Sigmoid & $355(28.8 \%)$ \\
\hline - Rectum & $195(15.8 \%)$ \\
\hline \multicolumn{2}{|l|}{ Size } \\
\hline - Diminutive polyps (4-5 mm) & $427(34.6 \%)$ \\
\hline - Small polyps (6-9mm) & $718(58.2 \%)$ \\
\hline - Polyps larger than $9 \mathrm{~mm}$ & $88(7.1 \%)$ \\
\hline \multicolumn{2}{|l|}{ Shape } \\
\hline \multicolumn{2}{|l|}{ - Diminutive polyps } \\
\hline - Flat/broad-based polyps & $419(98.1 \%)$ \\
\hline - Pedunculated polyps & $8(1.9 \%)$ \\
\hline \multicolumn{2}{|l|}{ - Small polyps } \\
\hline - Flat/broad-based polyps & $675(94 \%)$ \\
\hline - Pedunculated polyps & $43(6 \%)$ \\
\hline \multicolumn{2}{|l|}{ - Polyps >9mm } \\
\hline - Flat/broad-based polyps & $66(75 \%)$ \\
\hline - Pedunculated polyps & $22(25 \%)$ \\
\hline Number of patients with one polyp & $289(55.4 \%)$ \\
\hline Number of patients with two polyps & $103(19.7 \%)$ \\
\hline Number of patients with three polyps & $45(8.6 \%)$ \\
\hline Number of patients with more than three polyps & $85(16.3 \%)$ \\
\hline
\end{tabular}

$<5 \mathrm{~mm}$ (34.6\%); $7.1 \%$ were larger than $9 \mathrm{~mm}$. Most polyps were flat or broad-based. The percentage of pedunculated polyps increased with polyp size (diminutive polyps $(<5 \mathrm{~mm})$ $1.9 \%$; small polyps (6-9mm) $6 \%$, and polyps $>9 \mathrm{~mm} 25 \%$ ).

Most patients had one polyp, which was resected with cold snare (289 patients, 55.4\%); 103 patients had two polyps (19.7\%); 45 patients had three polyps (8.6\%); 85 patients had more than three polyps (16.3\%).

The efficacy of cold snare resection was $99.4 \%$ for all polyps. However, all failures observed (eight patients) occurred in the cecum ( $\triangleright$ Table 2 ), whereas in the rest of the colon, the success rate was $100 \%$. In the cecum, the success rate was only $90.2 \%$ of all cecal polyps. Only $0.49 \%$ of polypectomy procedures resulted in immediate post-polypectomy hemorrhage requiring endoscopic hemostasis with clip application. Cold snare resection was often associated with a marked vasoconstriction of the 
- Table2 Clip application and adverse effects after cold snare resection.

\begin{tabular}{|l|c|}
\hline \multicolumn{1}{|l|}{} & Number of polyps (\%) \\
\hline Clip application & $151(12.2 \%)$ \\
\hline " Prophylactic clip application & $6(0.49 \%)$ \\
\hline - Immediate post-polypectomy hemorrhage & \\
\hline Prophylactic clip application in & $25 / 427(5.9 \%$ group $)$ \\
\hline " Diminutive polyps & $103 / 718(24.3 \%$ group $)$ \\
\hline " Small polyps & $23 / 88(26.1 \%$ group $)$ \\
\hline " Polyps larger than 9 mm & \\
\hline Clip application for immediate post-polypectomy hemorrhage in & $0(0 \%)$ \\
\hline " Diminutive polyps & $2(0.27 \%$ group $)$ \\
\hline " Small polyps & $4(4.5 \%$ group $)$ \\
\hline " Polyps larger 9 mm & $1(0.08 \%)$ \\
\hline Perforation, clip application & $8(0.6 \%$ of all polyps, $9.8 \%$ of cecal polyps $)$ \\
\hline Failure of cold snare excision, only in cecum & \\
\hline Total number of polyps evaluated, $n=1233$. & \\
\hline
\end{tabular}

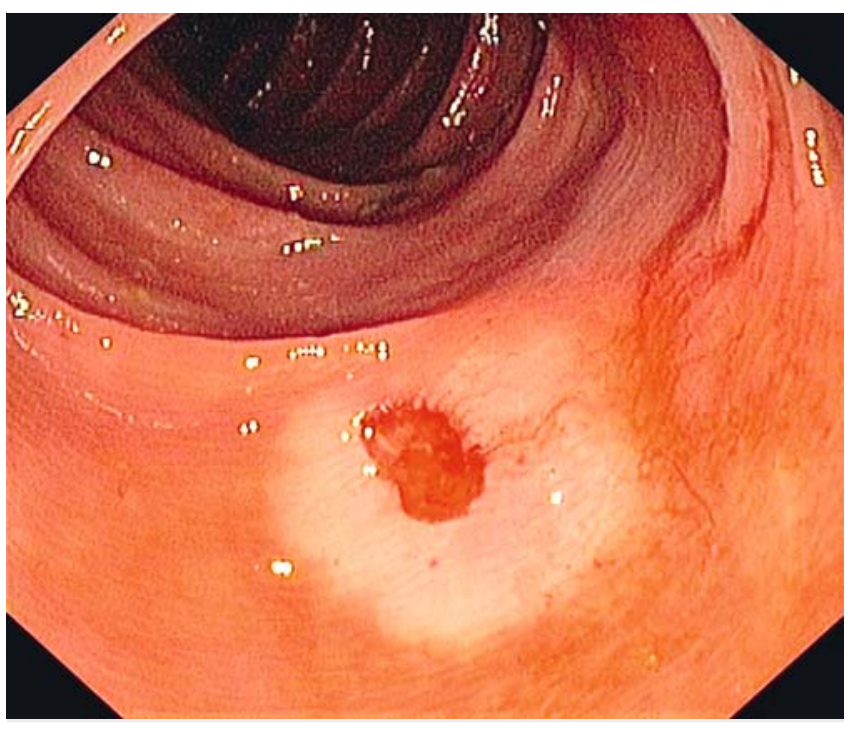

- Fig. 1 Ischemic reaction after cold snare resection.

surrounding mucosa ( $\boldsymbol{F}$ Fig. $\mathbf{1}$ ). We have defined immediate post-polypectomy bleeding as bleeding which was not self-limiting within 2 minutes and required additional interventional hemostasis as judged by the endoscopist. Active bleeding was successfully treated with hemostatic clipping in each patient. Immediate bleeding was more frequent in polyps larger than $9 \mathrm{~mm}$ compared with small polyps ( $4.5 \%$ vs $0.27 \%$ ). Clip application for bleeding prophylaxis was performed in 151 polyps (12.2\%) ( $\triangleright$ Table 2 ).

We defined delayed bleeding as bleeding requiring medical attention or emergency endoscopy (drop in hemoglobin). We did not encounter any relevant delayed bleeding. All patients were given a record sheet listing the gastrointestinal attendant

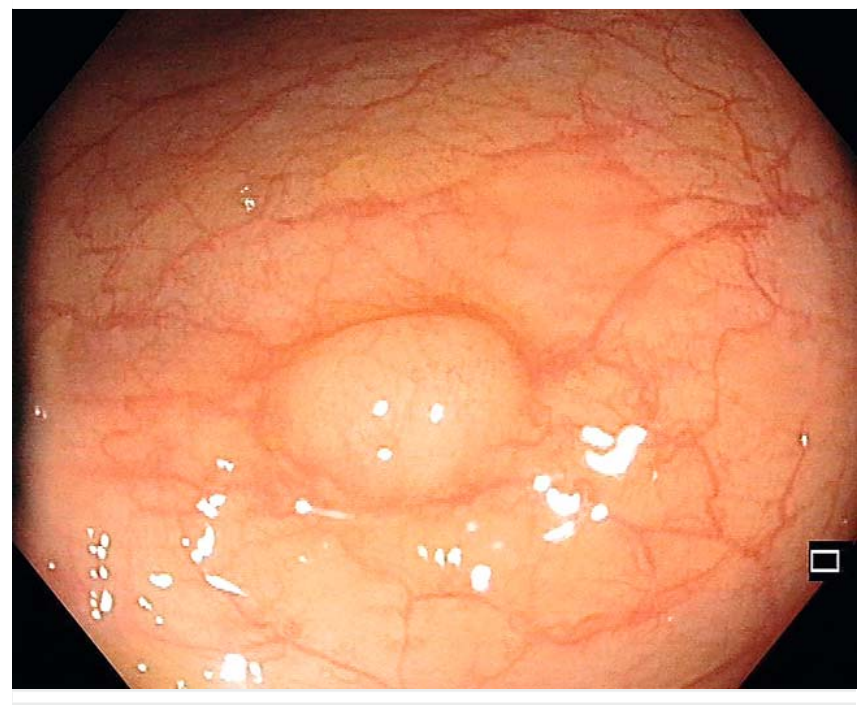

- Fig.2 Schwann cell tumor.

and the attending doctor. Patients were asked to report to that doctor if signs of bleeding occurred or were observed. We had no report of recurrent bleeding and no admission within 15 days of the colonoscopic procedure due to bleeding. As we are the only regional hospital offering emergency endoscopy, all patients with gastrointestinal bleeding are referred to our clinic.

Colonoscopic perforation occurred in one out of 1233 polyps $(0.08 \%)$. From the histologic work-up, this patient did not have a regular adenomatous polyp but a Schwann cell tumor ( $\triangleright$ Fig. 2); however, the perforation was detected immediately, endoscopic clipping was successfully performed, and no surgical management was required. 


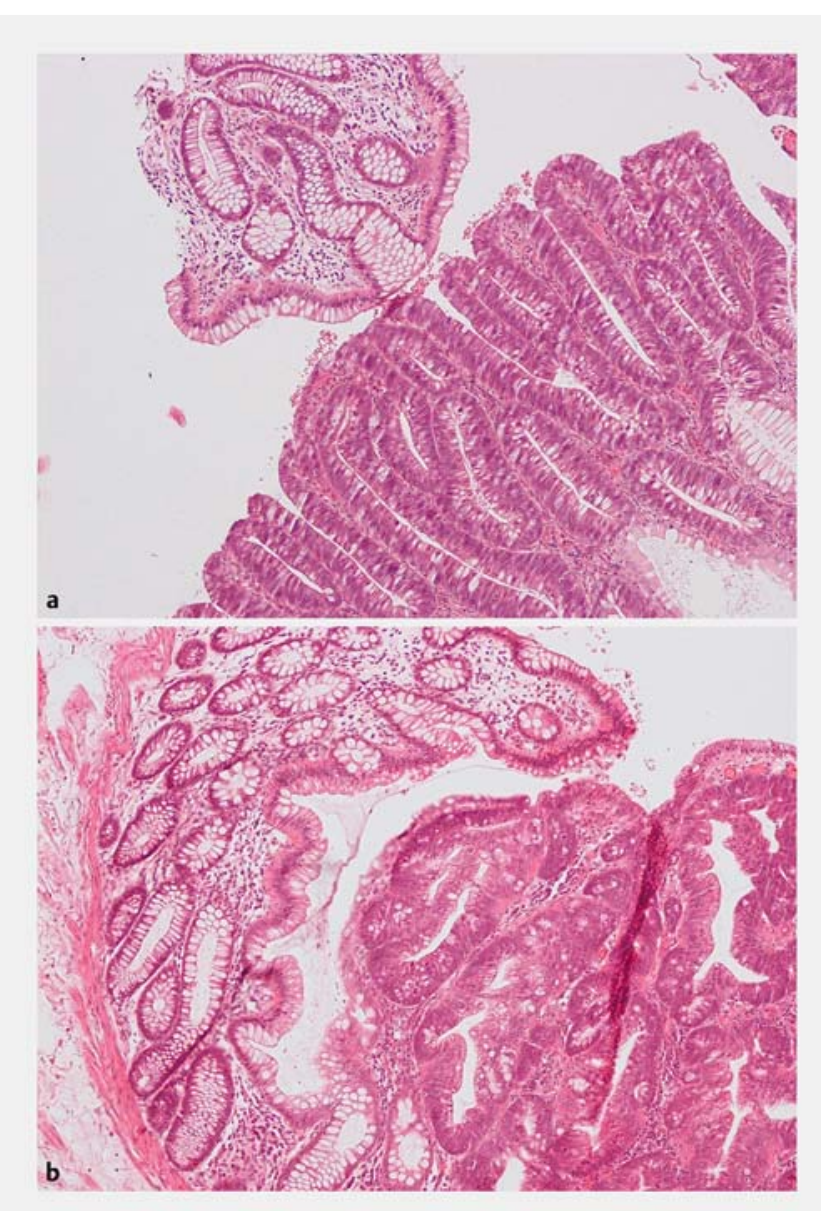

- Fig. 3 Histological examination. a Cold snare resection. b Thermal alteration after standard snare resection using electrocautery.
We compared 20 specimens $>5 \mathrm{~mm}$ diameter removed by cold or hot snare resection. Two pathologists analyzed the specimens with regard to complete removal and visible artifacts. We assumed that the absence of coagulation artifacts at the borders of specimens could lead to a better evaluation of the margins, which would have a bearing on whether there had been complete removal or not. However, there was no significant difference with respect to complete resection and evaluation of the polyp margins. Thermal alteration of tissue after hot snare resection was only noted in some patients ( $>$ Fig. $\mathbf{3 a}, \mathbf{b}$ ).

We compared the colonoscopic withdrawal time in 38 patients receiving standard hot snare excision to 195 patients undergoing cold snare resection. In order to ensure that withdrawal times were comparable, all patients with polyps larger than $15 \mathrm{~mm}$ were excluded. We also excluded all polyps smaller than $6 \mathrm{~mm}$ as these are not usually removed with the hot snare. Thus, the analysis is based only on patients with at least one polyp with size $\geq 6 \mathrm{~mm}$. Patients with polyps $<4 \mathrm{~mm}$ undergoing additional cold forceps biopsy were also excluded in the evaluation of withdrawal time. The mean size of the polyps in the cold snare group and in the hot snare group was almost identical (7.39 $\pm 3.77 \mathrm{~mm}$ vs $7.42 \pm 1.59 \mathrm{~mm}$, respectively; > Table 3 ). The mean colonoscopic withdrawal time was significantly shorter in the cold snare group compared to the hot snare group (27.6 minutes vs. 35.7 minutes, $P<0.01$ ) ( $\triangleright$ Fig. 4 ).

Examples of cold snare resection are shown in $\mathbf{F i g . 5 a , b . ~}$ Cold snare resection does not require prior submucosal injection of saline.

\section{Discussion}

Previously published data indicate that the post-polypectomy bleeding rate is in the range of $1 \%$. Recent studies have shown that cold snare polypectomy is a safe alternative procedure when compared to cold forceps removal of diminutive (up to $5 \mathrm{~mm})$ and small $(6-9 \mathrm{~mm})$ polyps $[6,12]$. Additionally, it has

- Table 3 Cold snare resection versus hot snare resection.

\begin{tabular}{|c|c|c|}
\hline & Cold snare resection ( $n=195$ patients) & Hot snare resection ( $n=38$ patients) \\
\hline \multicolumn{3}{|l|}{ Overall } \\
\hline - Polyps 6-9mm & 461 polyps ( $91.5 \%)$ & 71 polyps ( $85.5 \%)$ \\
\hline - Polyps $10-12$ or $10-14 \mathrm{~mm}^{1}$ & 43 polyps ( $8.5 \%)$ & 12 polyps ( $14.5 \%)$ \\
\hline - Average polyp size & $7.39 \mathrm{~mm}( \pm 3.77)$ & $7.42 \mathrm{~mm}( \pm 1.59)$ \\
\hline \multicolumn{3}{|l|}{ Location } \\
\hline - Cecum & 23 polyps ( $4.5 \%)$ & 4 polyps ( $4.8 \%)$ \\
\hline - Ascending colon & 81 polyps ( $16.1 \%)$ & 15 polyps ( $18.1 \%)$ \\
\hline - Transverse colon & 108 polyps ( $21.4 \%$ & 17 polyps ( $20.5 \%)$ \\
\hline - Descending colon & 60 polyps ( $11.9 \%)$ & 7 polyps ( $8.4 \%)$ \\
\hline - Sigmoid & 122 polyps ( $24.2 \%)$ & 31 polyps (37.3\%) \\
\hline - Rectum & 110 polyps ( $21.8 \%)$ & 9 polyps ( $10.8 \%)$ \\
\hline
\end{tabular}




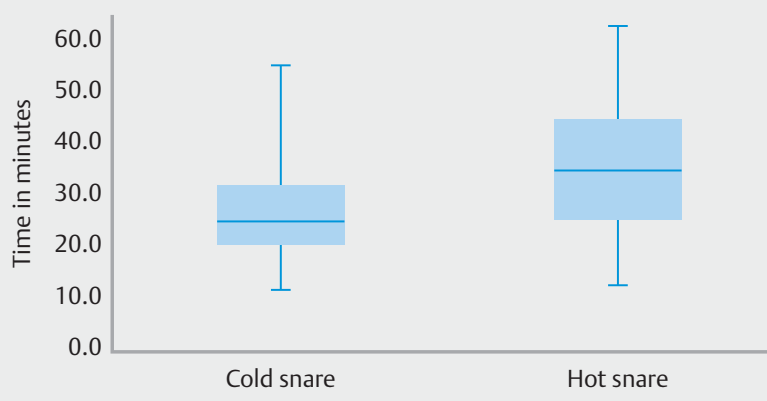

Fig. 4 Boxplots of withdrawal time (minutes) using cold snare and hot snare resection.

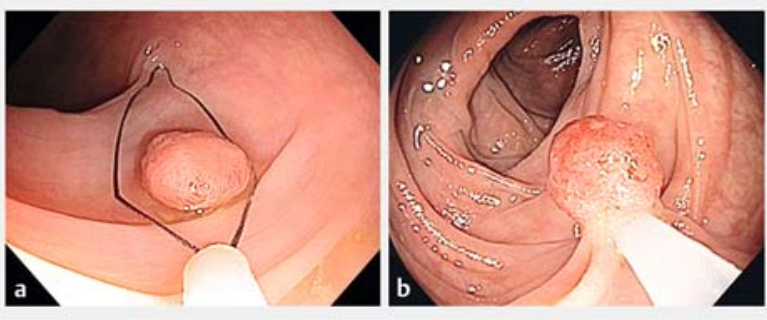

Fig.5a,b Examples of cold snare resection.

been shown that cold snare resection was associated with less bleeding than conventional hot snare resection in patients receiving anticoagulants. This was attributed to reduced alteration of submucosal arteries [10]. The current study has shown that cold snare resection is safe, even in polyps larger than $9 \mathrm{~mm}$ in diameter. Our findings indicate that cold snare polypectomy is associated with a low bleeding rate. Post-polypectomy hemorrhage occurred in only $0.49 \%$ of 1233 polypectomies, which is less than reported for conventional polypectomies. Bleeding occurred more frequently with increasing polyp size, but endoscopic clipping successfully treated all cases of bleeding. In other studies on cold snare resection, immediate postpolypectomy bleeding was reported in $4.1 \%$ of small polyps [4]. Lower immediate bleeding rates have been reported in large polyps, but that study only analyzed a relatively small number of resected polyps and all polyps removed were sessile [19]. In our study, $25 \%$ of all polyps $>9 \mathrm{~mm}$ were pedunculated, which could explain the difference, as pedunculated polyps might have an increased risk of bleeding. However, the bleeding rate is still very low, indicating that it may not be justified to limit cold snare resection to small and diminutive polyps or only to sessile polyps.

Interestingly, cold snare resection was often associated with a marked vasoconstriction of the surrounding mucosa, which was not touched or affected by the snare ( $\triangleright$ Fig. $\mathbf{1})$. This reactive vasoconstriction most likely contributes to the hemostasis observed after cold snare resection. The pronounced vasoconstriction shown was not observed in all patients.
This vasoconstriction is most likely caused by a local neurologic reflex (axon reflex) in response to mucosal injury [20]. We could not explain why this vasoconstriction occurred in such a pronounced manner in some patients. This vasoconstriction can also be observed after cold biopsy. It is not clear whether there is a connection with the different modes of dermographism.

Cold snare resection of small and diminutive polyps resulted in higher rates of complete resection when compared to cold biopsy. Additionally, this was achieved in a shorter procedure time [6]. In our study, we could confirm that cold snare resection is even superior to standard hot snare resection as shown by a significant reduction in colonoscopic withdrawal time.

A further positive aspect of cold snare polypectomy is the absence of electrocautery leading to histopathological artifacts on polyp margins. However, our histopathological findings showed no relevant difference between cold and hot snare resection. A better histological quality of excised polyps was only noted in some patients, which nevertheless did not influence the histologic outcome if complete resection was achieved.

Another major adverse effect of polypectomy is perforation. Recently reported perforation rates vary from $0.016 \%$ in all diagnostic colonoscopies [21] up to $5 \%$ in therapeutic colonoscopies $[22,23]$. In cold snare polypectomy, the absence of electrocautery and thermal injury reduces the possibility of perforation, confirmed by a perforation rate in the current study of $0.08 \%$ in all colonoscopies with polypectomy. The perforation observed in the present study was most likely due to an unusual histologic polypoid tumor, which proved to be an exophytic schwannoma.

In the cecum, the feasibility of cold snare resection is reduced, especially in the area close to the orifice of the appendix (failure in $9.8 \%$ of cecal polyps; - Table 2 ). The reason for the failure rate is unclear. Whether the submucosa in the cecum has an increased amount of connective tissue, which precludes successful use of the cold snare, is not proven and warrants further investigation.

In conclusion, this study shows that cold snare polypectomy is a safe endoscopic procedure with a lower risk of post-polypectomy bleeding and perforation than in conventional polypectomy. The technical feasibility of cold snare resection distal to the ileocecal valve was $100 \%$. Due to the reduced procedure time, cold snare resection leads to increased efficacy of screening colonoscopy. Therefore cold snare resection should be the preferred method for polyp removal of diminutive, small and larger polyps (up to $15 \mathrm{~mm}$ ) in screening colonoscopy.

\section{Acknowledgments}

We are grateful to Dr Fulghum for proofreading the manuscript.

\section{Competing interests}

None 


\section{References}

[1] Winawer S], Zauber AG, Ho MN et al. Prevention of colorectal cancer by colonoscopic polypectomy. The National Polyp Study Workgroup. NEJM 1993; 329: 1977-1981

[2] Singh N, Harrison M, Rex DK. A survey of colonoscopic polypectomy practices among clinical gastroenterologists. Gastrointest Endosc 2004; 60: 414-418

[3] Levin TR, Zhao W, Conell C et al. Complications of colonoscopy in an integrated health care delivery system. Ann Intern Med 2006; 145: $880-886$

[4] Regula J, Rupinski M, Kraszewska E et al. Colonoscopy in colorectalcancer screening for detection of advanced neoplasia. NEJM 2006; 355: $1863-1872$

[5] Tolliver KA, Rex DK. Colonoscopic polypectomy. Gastroenterol Clin North Am 2008; 37: 229-251, ix

[6] Lee CK, Shim JJ, Jang JY. Cold snare polypectomy vs. cold forceps polypectomy using double-biopsy technique for removal of diminutive colorectal polyps: a prospective randomized study. Am J Gastroenterol 2013; 108: $1593-1600$

[7] Draganov PV, Chang MN, Alkhasawneh A et al. Randomized, controlled trial of standard, large-capacity versus jumbo biopsy forceps for polypectomy of small, sessile, colorectal polyps. Gastrointest Endosc 2012; 75: $118-126$

[8] Pohl H, Srivastava A, Bensen SP et al. Incomplete polyp resection during colonoscopy - results of the complete adenoma resection (CARE) study. Gastroenterology 2013; 144: $74-80$, e71

[9] Van Gossum A, Cozzoli A, Adler M et al. Colonoscopic snare polypectomy: analysis of 1485 resections comparing two types of current. Gastrointest Endosc 1992; 38: 472-475

[10] Horiuchi A, Nakayama Y, Kajiyama M et al. Removal of small colorectal polyps in anticoagulated patients: a prospective randomized comparison of cold snare and conventional polypectomy. Gastrointest Endosc 2014; 79: 417-423

[11] Tappero G, Gaia E, De Giuli P et al. Cold snare excision of small colorectal polyps. Gastrointest Endosc 1992; 38: 310 - 313
[12] Repici A, Hassan C, Vitetta E et al. Safety of cold polypectomy for $<10 \mathrm{~mm}$ polyps at colonoscopy: a prospective multicenter study. Endoscopy 2012; 44: 27 - 31

[13] Ichise Y, Horiuchi A, Nakayama Y et al. Prospective randomized comparison of cold snare polypectomy and conventional polypectomy for small colorectal polyps. Digestion 2011; 84: $78-81$

[14] Choksi N, Elmunzer B], Stidham RW et al. Cold snare piecemeal resection of colonic and duodenal polyps $\geq 1 \mathrm{~cm}$. Endosc Int Open 2015; 3: $\mathrm{E} 508-513$

[15] Din S, Ball A], Riley SA et al. A randomized comparison of cold snare polypectomy versus a suction pseudopolyp technique. Endoscopy 2015; 47: $1005-1010$

[16] Kim JS, Lee BI, Choi H et al. Cold snare polypectomy versus cold forceps polypectomy for diminutive and small colorectal polyps: a randomized controlled trial. Gastrointest Endosc 2015; 81: 741 - 747

[17] Park SK, Ko BM, Han JP et al. A prospective randomized comparative study of cold forceps polypectomy by using narrow-band imaging endoscopy versus cold snare polypectomy in patients with diminutive colorectal polyps. Gastrointest Endosc 2016; 83: 527 - 532 e521

[18] Gomez V, Badillo RJ, Crook JE et al. Diminutive colorectal polyp resection comparing hot and cold snare and cold biopsy forceps polypectomy. Results of a pilot randomized, single-center study (with videos). Endosc Int Open 2015; 3: E76-80

[19] Muniraj T, Sahakian A, Ciarleglio MM et al. Cold snare polypectomy for large sessile colonic polyps: a single-center experience. Gastroenterol Res Pract 2015; 2015: 175959

[20] Vanner S, Surprenant A. Neural reflexes controlling intestinal microcirculation. Am J Physiol 1996; 271: G223-230

[21] Rathgaber SW, Wick TM. Colonoscopy completion and complication rates in a community gastroenterology practice. Gastrointest Endosc 2006; 64: $556-562$

[22] Damore L] 2nd, Rantis PC, Vernava AM et al. Colonoscopic perforations. Etiology, diagnosis, and management. Dis Colon Rectum 1996; 39: $1308-1314$

[23] Repici A, Pellicano R, Strangio G et al. Endoscopic mucosal resection for early colorectal neoplasia: pathologic basis, procedures, and outcomes. Dis Colon Rectum 2009; 52: 1502-1515 